There is still no single reliable assessment for monitoring drug response in rheumatoid arthritis and a number of assessments are used (Dudley Hart and Huskisson, 1972). In this trial a diurnal pain score was used in addition to the other standard measurements, and it was found that both drugs produced a statistically significant reduction in the pain level. The measurement of finger stiffness has previously been correlated with morning stiffness (Ingpen, 1968), and a similar correlation was found with the aspirin group in the present study. The lack of correlation in the benorylate group may have been due to the small number of patients (12) completing this assessment.

The results of the study have shown that both drugs produced a statistically significant improvement in the clinical response but that there was no detectable difference between the two drugs: side effects occurred more often in the aspirin group but the difference was not significant and in both groups were less common in the second week of treatment.

In conclusion, this study has confirmed the efficacy of benorylate in rheumatoid arthritis and has shown that the twice-daily administration is as effective as the administration of aspirin four times daily. This convenience of administration together with the absence of gastrointestinal bleeding suggest that benorylate is a suitable alternative treatment for rheumatoid arthritis.
We thank the pharmacy department at Guy's Hospital and at New Cross Hospital for arranging the administration of the drugs. We also thank Dr. J. T. Nicholls and Mrs. H. R. Lane who performed the statistical analysis, for their continued help.

\section{References}

Boardman, P. L., and Hart, F. D. (1967). British Medical fournal, 4, 264. Cardoe, N. (1970). Clinical Trials fournal, 7, 313.

Cromie, B. W. (1963). Lancet, 2, 994.

Cuddigan, J. H. P. (1971). VII European Rheumatology Congress. Abstract No. $45 / 7$.

Franke, M., and Manz, G. (1972). Current Therapeutic Research, 14, 113

Hart, F. D., and Huskisson, E. C. (1972). Lancet, 1, 28.

Ingpen, M. L. (1968). Annals of Physical Medicine, $9,322$.

Ingpen, M. L., and Hume Kendall, P. (1968). Annals of Physical Medicine, 9, 203.

Ritchie, D. M., et al. (1968). Quarterly fournal of Medicine, 147, 393.

Robertson, A. (1971). VII European Rheumatology Congress. Abstract No. $45 / 4$.

Ropes, M. W., Bennett, G. A., Cobb, C., Jacox, R., and Jessar, R. A. (1959), Annals of Rheumatic Diseases, 18, 49

Rosner, I., Malhie, P.. and Mottot, G. (1968). Thérapie, 23, 525.

Sperryn, P. N., Nicholson, P. A., Parsons, V., and Hamilton, E. B. D. (1971), VII European Rheumatology Congress. Abstract No. 45/3.

Steinbrocker, O., Traeger, C. H., and Batterman, R. C. (1949). Fournal of the American Medical Association, 140, 659.

\title{
Reported Influenza in Pregnancy and Subsequent Cancer in the Child
}

\author{
JEAN FEDRICK， EVA D. ALBERMAN
}

\section{British Medical fournal, 1972, 2, 485-488}

\section{Summary}

A longitudinal study of 1,959 infants born in the first week of March 1958 to mothers who were reported to have had influenza during pregnancy revealed an incidence of cancer of 4.1 per 1,000 compared with only 0.8 per 1,000 among the 14,791 infants of mothers who had not had influenza.

This increase was caused by cases of leukaemia and other neoplasms of lymphatic and haematopoietic tissue (I.C.D. 200-209) $(P<0.0001)$.

Data from the reports of the Registrar General for England and Wales were used to estimate the number of infants born in each year from 1955 to 1964 who subsequently died of cancer before 5 years of age. The rates for each year were compared with an estimate of the prevalence of influenza during the preceding winter. After allowing for the overall trend in the cancer death rate, a highly significant correlation was shown with deaths attributed to causes classified as I.C.D. 200-209 (P $<0.005$ ), but not with deaths attributed to other cancers. The increase in the risk of developing these neoplasms among children whose mothers had influenza is estimated to be not less than fourfold. Even so the risk remains small (3 to 4 per 1,000 ).

Unit of Clinical Epidemiology, Department of the Regius Professor of Medicine, University of Oxford

JEAN FEDRICK, M.A., Research Epidemiologist

Department of Public Health, London School of Hygiene and ropical Medicine, London

EVA D. ALBERMAN, M.D., D.P.H., Senior Lecturer

\section{Introduction}

Ever since the classic papers of the Oxford Survey of Childhood Cancers (Stewart, Webb, and Hewitt, 1958; Stewart, 1961) implicating abdominal $x$-ray examination during pregnancy with the development of cancer in the child, it has been thought feasible to postulate an association between cancer in childhood and events that occurred in utero. This possibility has been thrown into prominence recently by the striking study of Herbst, Ulfelder, and Poskanzer (1971) which provided evidence for an association between the rare adenocarcinoma of the vagina presenting in the late teens and early twenties and maternal stilboestrol therapy during pregnancy.

In the first report of the Oxford survey concerning childhood deaths from cancer in England and Wales over a two-year period, Stewart et al. (1958) showed an excess of the mothers of the children with cancer reporting a viral infection during pregnancy compared with the control mothers. More recently a neonatal leukaemia death has been reported with a history of the mother having had an influenza-like illness early in the second trimester (Miller, Newstead, and Young, 1969).

The first part of the present study was initially undertaken in an effort to ascertain the effects of maternal illness during pregnancy on the subsequent outcome of the pregnancy and the future health of the child. To our knowledge no previous study has looked longitudinally at the possibility of maternal infection in pregnancy being related to the subsequent development of childhood cancer. The second part of the study constitutes an attempt to confirm the positive findings by determining whether there is any correlation between the number of births of children who are destined to die of cancer and preceding epidemics of influenza. 


\section{Longitudinal Study}

\section{POPULATION AND METHODS}

The data were obtained by the 1958 British Perinatal Mortality Survey (Butler and Bonham, 1963; Butler and Alberman, 1969) and its continuation, the National Child Development Study (Davie, Butler, and Goldstein, 1972). Questionnaires were completed for about $98 \%$ of notified births for England and Wales and registered births for Scotland occurring in the week 3-9 March 1958. These questionnaires from 17,204 mothers related to 17,418 babies. The questionnaires, which were filled in by the midwives soon after birth, included a section on maternal illness during pregnancy. One of the questions specifically asked was whether the mother had had influenza and, if so, in which week of the pregnancy. No attempt was made to corroborate this history, the pregnancies occurred during the influenza pandemic at the end of 1957 and beginning of 1958 , and positive histories are likely to have been correct.

Of the 17,418 total births studied in this week, 668 were either stillborn or died within the first four weeks of life (Table I).

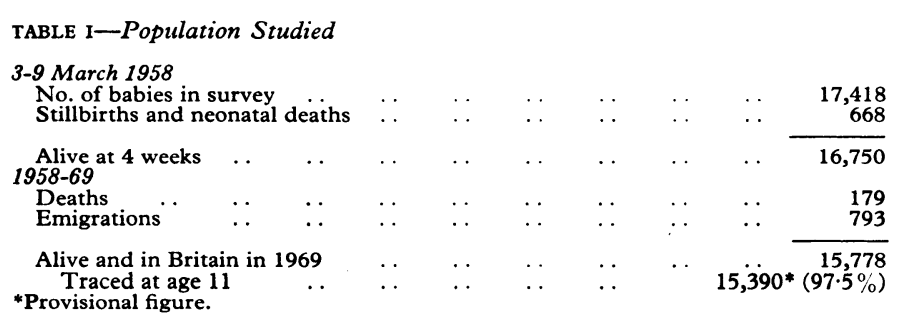

Of the 15,778 children alive and resident in Britain at the age of $11,15,390(97 \cdot 5 \%)$ were contacted. In addition, 370 of the 793 children who had emigrated by age 11 were still in Britain at age 7 and were included in the first follow-up carried out at that time. For the majority of children a medical history and examination was recorded at both ages. In all, 179 children are known to have died between 4 weeks and 11 years of age, and for these the certified cause of death was made available. Details of all cases ascertained as having leukaemia were obtained from the cancer registries and individual physicians.

\section{RESULTS}

This study is concerned with the 16,750 children who survived the neonatal period (Table II). A history of maternal influenza during pregnancy was recorded for $1,959(12 \%)$ of these. This proportion was higher than usual owing to the pandemic of Asian influenza which occurred during the winter of 1957-8.
TABLE II-Children Who Survived Neonatal Period

\begin{tabular}{|c|c|c|c|}
\hline & $\begin{array}{l}\text { Population } \\
\text { at Risk }\end{array}$ & $\begin{array}{l}\text { Cases of } \\
\text { Cancer }\end{array}$ & $\begin{array}{c}\text { Rate per } \\
1,000\end{array}$ \\
\hline $\begin{array}{l}\text { Infants of mothers with influenza } \\
\text { Infants of mothers without influenza }\end{array}$ & $\begin{array}{r}1,959 \\
14,791\end{array}$ & $\begin{aligned} 8 & (7) \\
12 & (6)\end{aligned}$ & $\begin{array}{l}4 \cdot 1(3.6) \\
0.8(0.4)\end{array}$ \\
\hline Total. . & 16,750 & $20(13)$ & $1.2(0.8)$ \\
\hline
\end{tabular}

The numbers of cases with I.C.D. 200-209 and the corresponding rates are shown in parentheses.

Of the 1,959 infants for whom a history of maternal influenza during pregnancy was recorded, eight are known to have developed cancer-that is, an incidence of $4 \cdot 1$ per 1,000 , with standard error 1.4. Of the 14,791 infants whose mothers were not noted to have had influenza during pregnancy, 12 developed cancer-that is, an incidence of 0.8 per 1,000 , standard error $0 \cdot 2$. In the present survey, therefore, there was a fivefold increase in the incidence of cancer among children born to women with a history of influenza $(P<0.001)$.

Details of the cases are listed in Table III. It is notable that seven of the eight cancers in the group with the history of maternal influenza were neoplasms of lymphatic and haematopoietic tissue (I.C.D. 200-209) compared with 6 of the 12 cases without this history. If only the cases classified under I.C.D. 200-209 are considered, the incidence among infants of mothers who had had influenza was 3.6 per 1,000 compared with 0.4 per 1,000 among infants of mothers without this history $(P<0.0001)$ -that is, a ninefold increase. The incidence of other types of cancer was almost identical in the two groups $(0.5$ and 0.4 per 1,000 respectively).

A calculation of the expected number of children registerec as having cancer classified under I.C.D. 200-209 by the age of 10 years was derived from the reports from cancer registries in England and Wales for the years 1963-6 (Doll, Muir, and Waterhouse, 1970). Using these data one can calculate that among the 14,791 infants without a history of maternal influenza, a total of about seven cases would be expected to have this diagnosis, compared with the six observed. We therefore feel justified in considering the incidence in the non-influenza group to be typical of the population as a whole.

The number of deaths in the influenza group was small and the excess may have been partly due to chance. It is unlikely, however, that this risk of developing a neoplasm of the lymphatic or haematopoietic tissues was less than 1.7 per 1,000 ( $P<0.05)$ or that the increase in risk, in comparison with that calculated from the cancer registry data, was less than fourfold.

The data were examined to ascertain whether the incidence of cancer was altered with the trimester in which the influenza was said to have occurred. There was no evidence to suggest that infants of mothers affected in any one trimester of preg-

TABLE III-Listing of all Cases of Cancer

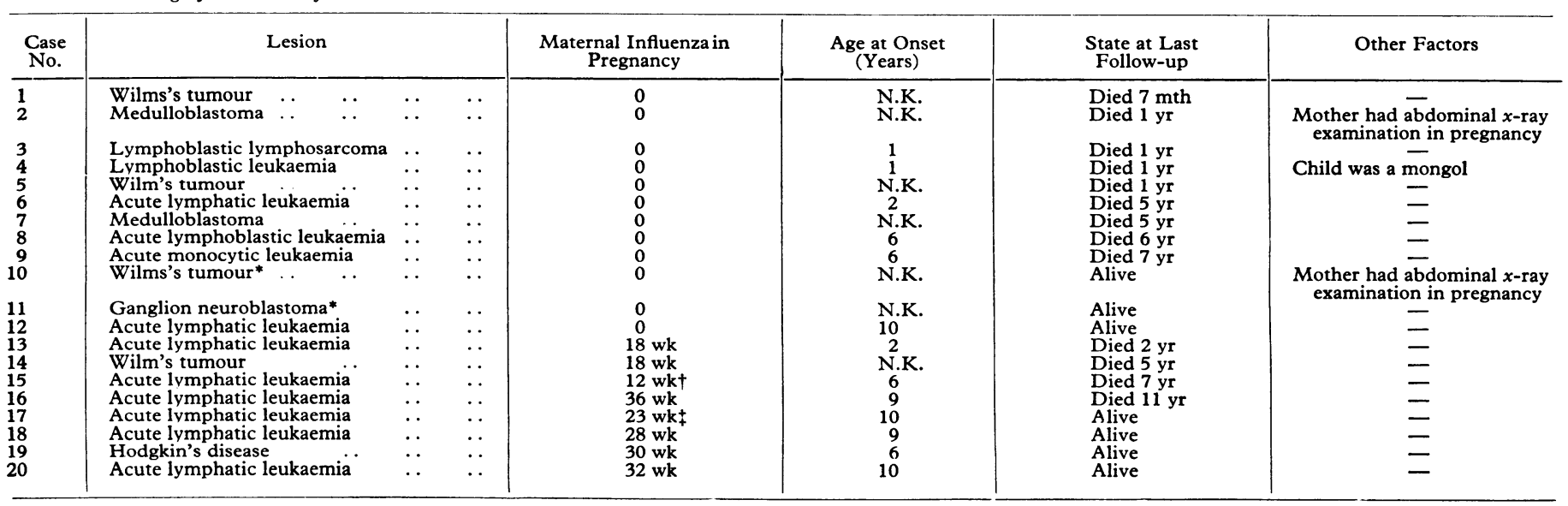


TABLE IV-Correlation of Estimated Rate per 100,000 Births of Deaths Due to Cancer before the Age of 5 with a Measure of the Prevalence of Influenza in the Preceding Winter

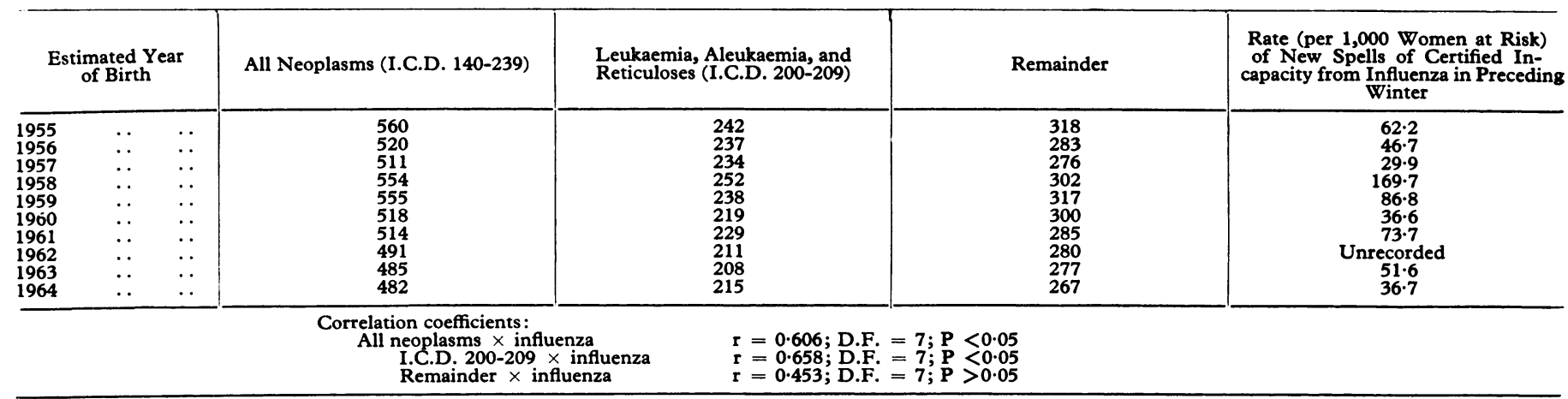

nancy are more likely to develop cancer than those affected in any other.

An examination of the ages of onset of the six cases of I.C.D. 200-209 where there was no history of maternal influenza revealed a mean onset of 4.3 years, whereas when there was a history of influenza the mean onset of symptoms occurred at 7.4 years. The difference between the mean ages, however, is not statistically significant.

We have been unable to demonstrate any difference which distinguished the two groups of children other than the history of maternal influenza. Mortality rates at ages 1 month to 7 years were closely similar (influenza group, 15 deaths, 7.7 per 1,000; other children, 135 deaths, $9 \cdot 1$ per 1,000 ) and the social class, parity, and age distributions of the mothers were almost identical.

\section{Retrospective Study of Perinatal Deaths}

In addition to the study of all births occurring in the first week of March 1958, the British Perinatal Mortality Survey included some $94 \%$ of the stillbirths and neonatal deaths-that is, deaths within 28 days of delivery-occurring in Britain in the rest of March and in the following April and May. Of the 7,851 deaths studied in this way, some $68 \%$ were examined at necropsy and two infants were recorded as having died of leukaemia.

Questionnaires, identical to those used in the previous study, were filled in, with details of maternal illnesses during pregnancy, by the midwives, but only after the infant was known to have died-that is, the information was collected retrospectively. Of the two patients with leukaemia (both confirmed at necropsy), one died 15 minutes after being delivered, the mother having been noted to have had influenza at the 13th week followed by bronchitis which was treated with penicillin. The other patient died at 21 days with acute monocytic leukaemia, no maternal illnesses having been reported.

\section{Secular Analyses}

A further analysis was undertaken to discover whether infants in utero during periods of major influenza epidemics had an increased risk of dying of cancer. For this purpose the prevalence of influenza in England and Wales during each winter was compared with the number of children born during the following year who subsequently died of cancer.

It is not possible to ascertain the precise year of birth of each child dying of cancer from the published statistics of the Registrar General for England and Wales, although the child's age in years at death is given, up to age 4 years. Thus, given an infant who died, say, in 1954 at the age of 4 , it is possible only to be sure that his date of birth was between January 1949 and December 1950. We have therefore allocated one-half of the total number of deaths of the 4-year-olds occurring in 1954 to year of birth 1949, and the other half to 1950 .
Rates were computed in this way for all infants presumed to have been born in each year from 1955 to 1963 and who died of cancer under 5 years of age (Table IV). These rates were then compared with the rates of spells of incapacity certified as due to influenza among employed women during the 12-month period beginning with the first Monday in June of the preceding year (Ministry of Pensions and National Insurance, 1954-7; Department of Health and Social Security, 1969).

As can be seen from Table IV, there is a positive correlation between the estimated death rate for the cohort born in each year with the prevalence of influenza in the preceding winter. This correlation is significant at the $5 \%$ level. When the death rate is specified by the site of the neoplasm the correlation is significant only for I.C.D. 200-209.

There is, however, an overall secular decrease in the death rate due, we suspect, to the prolongation of life resulting from improvements in treatment. If this overall trend is allowed for, ${ }^{*}$

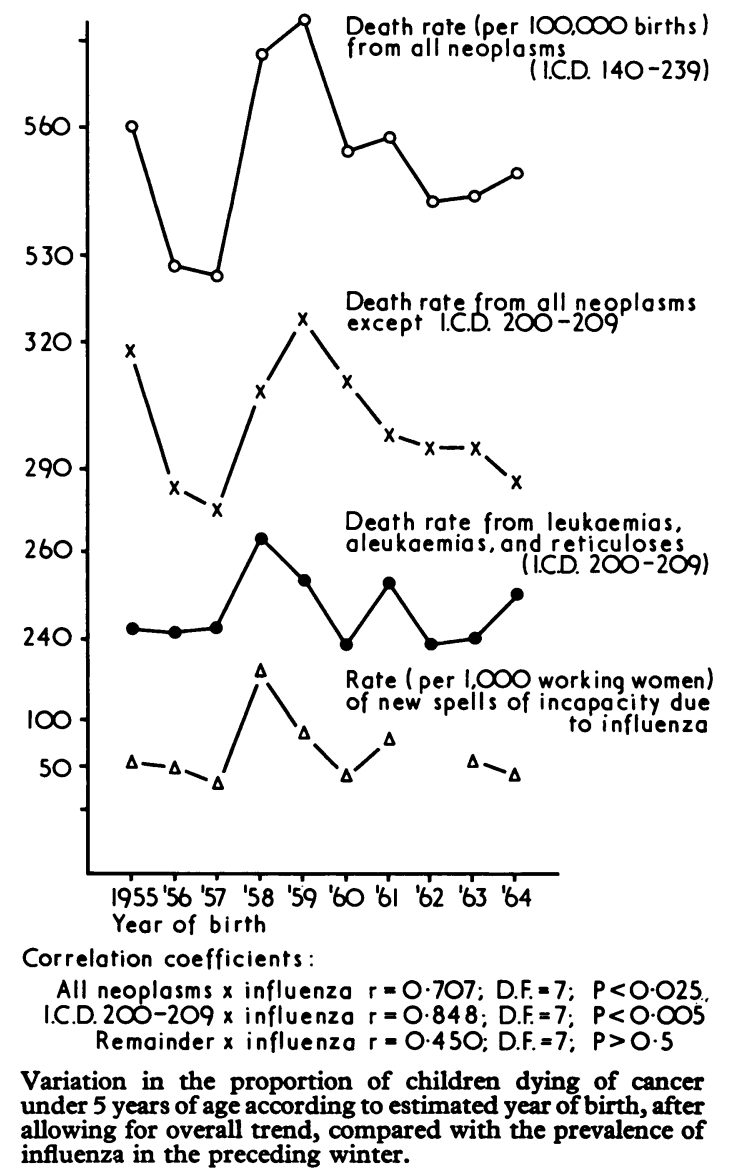

*By using the transformation $Z_{t}=Y_{t}-(t-1) b$, where $Y_{t}$ is the observed number of cases in the $t^{\prime}$ th year and $b$ is the slope of the regression line fitting the data. 
one then obtains the rates depicted in the Chart. The correlation $(0.71)$ between the number of infants who die of cancer and the prevalence of influenza in the year preceding their birth can now be seen to be statistically highly significant. The correlation for cases of neoplasms of the lymphatic and haematopoietic tissue (I.C.D. 200-209) is higher still (0.85), and if cases of leukaemia alone (I.C.D. 204) are considered the correlation is also statistically significant $(r=0.78, D . F .=7, P<0.01)$. The correlation with other neoplasms, although positive, is not statistically significant.

\section{Discussion}

Our analyses suggest that viral infection in utero could be a factor of importance in the aetiology of leukaemia. It is not possible to state categorically that the infection concerned was due to an influenza virus, although the epidemiological evidence makes this highly likely.

It has been shown experimentally (Seim, Ly, Imagawa, and Adams, 1960) that one strain (the neurotropic strain) of the influenza A virus does not cross the placental barrier in mice, but that another strain of the same virus does so, but only in the third trimester. Clearly, the factors responsible for transplacental viral passage are largely unknown.

It is possible that the effect of viral infection in utero is related to the consequences of the maternal infection rather than to the direct effect of the virus itself. For example, it is known that certain acute infections such as influenza are accompanied by a profound systemic toxaemia and, often, a reduction in the arterial oxygen saturation (Hardy, Ararowicz, Mannini, Medearis, and Cooke, 1961). Alternatively, the effect could be due to that of drugs taken by the mother at the time.

It should be stressed, however, that although the relative risk of childhood leukaemia appears to be raised after such an infection during pregnancy, the absolute risk, even after such a history, is still very low, between 3 and 4 per 1,000 children under 12 years.

We thank all the medical officers of health and their staff for their help; the Executive Committee of the National Birthday Trust Fund and the National Child Development Study for permission to use their data; Professor Neville Butler, without whom the initial survey would never have taken place; Dr. C. Peckham and Professor R. Pearson, who went through the 11-year-old questionraires; the cancer registries and physicians who supplied details of the leukaemia cases; and many colleagues for constructive advice, including Dr. Alice Stewart, Mr. G. Draper, Dr. J. A. Baldwin, and especially Dr. M. C. Pike and Professor Sir Richard Doll. This work was supported in part by the National Fund for Research into Crippling Diseases.

Requests for reprints should be sent to Mrs. Jean Fedrick, Oxford Regional Hospital Board, Old Road, Headington, Oxford.

\section{References}

Butler, N. R., and Alberman, E. D. (1969). Perinatal Problems, Edinburgh, Livingstone.

Butler, N. R., and Bonham, D. G. (1963). Perinatal Mortality. Edinburgh, Livingstone.

Davie, R., Butler, N. R., and Goldstein, H. (1972). From Birth to Seven. London, Longman. In press.

Department of Health and Social Security (1969). Digest of Health Statistics for England and Wales. London, H.M.S.O.

Doll, R., Muir, C., and Waterhouse, J. (1970). Cancer Incidence in Five Continents, vol. II. Berlin, Springer.

Hardy, J. M. B., Ararowicz, E. N., Mannini, A., Medearis, D. N., and Cooke, R. E. (1961). American fournal of Public Health and the Nation's Health, 51,1182 .

Herbst, A. L., Ulfelder, H., and Poskanzer, D. C. (1971). New England fournal of Medicine, 284, 878.

Miller, D. R., Newstead, G. J., and Young, L. W. (1969). Fournal of Pediatrics, 74, 300.

Ministry of Pensions and National Insurance (1954-7). Digest of Statistics. London, H.M.S.O.

Seim, R. A., Ly, H., Imagawa, D. T., and Adams, J. M. (1960). Fournal of Neuropathology and Experimental Neurology, 19, 125.

Stewart, A. (1961). British Medical fournal, 1, 452

Stewart, A., Webb, J., and Hewitt, D. (1958). British Medical fournal, 1, 1495.

\section{Lead Poisoning in Rural Scotland}

\section{A. D. BEATTIE, J. H. DAGG, \\ A. GOLDBERG, \\ I. WANG, J. RONALD}

British Medical Fournal, 1972, 2, 488-491

\section{Summary}

Nine people from four families living in rural parts of Scotland have been found to suffer from clinical or biochemical effects of lead poisoning. Five had symptoms and four had unequivocal evidence of excessive lead exposure. The source of lead has been traced to the domestic water supply which in all cases was grossly contaminated with lead acquired from lead plumbing systems, including lead storage tanks. Clinical improvement followed the replacement of lead piping in two families studied. Lead poisoning is a possible cause of chronic ill health in areas of plumbosolvent water.

M.R.C. Group in Iron and Porphyrin Metabolism, Stobhill Hospital, Glasgow

A. D. BEATTIE, M.B., CH.B., Honorary Registrar

A. GOLDBERG, M.D., F.R.C.P., F.R.S.ED., Regius Professor of Materia Medica University Department of Medicine, Western Infirmary, Glasgow,
W.1

J. H. DAGG, M.D., F.R.C.P., Consultant Physician

Victoria Infirmary, Glasgow

I. WANG, M.B., F.R.C.P. Consultant Physician

Royal Northern Infirmary, Inverness

J. RONALD, M.D., F.R.C.P., Consultant Physician

\section{Introduction}

Lead poisoning is a well-recognized industrial hazard, particularly among ship breakers, scrap-metal workers, and battery manufacturers. Domestic lead poisoning is less common apart from the well-known hazard in children (Moncrieff et al., 1964; Gibson et al., 1967). It was shown by Crawford and Morris (1967) that domestic water is sometimes contaminated by lead, but there are few reports of clinical lead poisoning as a consequence. Three severe cases from Yorkshire were described by Bacon et al. (1967). This paper describes four households with lead intoxication acquired from contamination of the domestic water supply. All four families lived in rural parts of the Scottish Highlands.

\section{Patients and Methods}

The patients were referred by their general practitioners for investigation to the Royal Northern Infirmary, Inverness, the Victoria Infirmary, Glasgow, and the Western Infirmary, Glasgow.

Blood lead and water lead levels were estimated by the dithizone method. Erythrocyte protoporphyrin was measured by the method of Rimington (1961). Urinary delta-aminolaevulic acid (ALA) and porphobilinogen were measured by the method of Mauzerall and Granick (1956). 